\title{
Pre-hospital Delay and Its Reasons in Patients With Acute Myocardial Infarction Presenting to a Primary Percutaneous Coronary Intervention- Capable Center
}

Syed F. Mujtaba ${ }^{1}$, Hina Sohail ${ }^{1}$, Jaghat Ram ${ }^{2}$, Muhammad Waqas ${ }^{3}$, Muhammad Hassan ${ }^{2}$, Jawaid A. Sial ${ }^{4}$ , Khalid Naseeb ${ }^{4}$, Tahir Saghir ${ }^{4}$, Musa Karim ${ }^{5}$

1. Adult Cardiology, National Institute of Cardiovascular Diseases, Karachi, PAK 2. Cardiology, National Institute of Cardiovascular Diseases, Larkana, PAK 3. Interventional Cardiology, National Institute of Cardiovascular Diseases, Karachi, PAK 4. Cardiology, National Institute of Cardiovascular Diseases, Karachi, PAK 5. Statistics, National Institute of Cardiovascular Diseases, Karachi, PAK

Corresponding author: Syed F. Mujtaba, s.fayazmujtaba@gmail.com

\section{Abstract \\ Objective}

This study aimed to assess the duration of pre-hospital delay among ST-Segment Elevation Myocardial Infarction (STEMI) patients and its contributing factors.

\section{Methodology}

A cross-sectional study was conducted at Rural Satellite Center in Larkana, Pakistan from May to September 2020. A total of 240 STEMI patients who underwent primary percutaneous coronary intervention (P-PCI) were included. The patients' demographic characteristics, index event characteristics, mode of transportation, misinterpretations, misdiagnoses, and financial problems were recorded. Data were analyzed using SPSS version 22.0 (IBM Corp., Armonk, NY, USA).

\section{Results}

The observed pre-hospital time was 120 minutes; 229 (median; interquartile range [IQR]). It was found that $33.3 \%$ of patients arrived within one hour of the symptom onset, while $20.4 \%$ of patients delayed hospital arrival for more than six hours. The delay rate was highest among patients aged 41 to 65 years. Moreover, delayed admissions were more common among females as compared to males $(\mathrm{p}=0.008)$. Among the causes of delay in hospital arrival were misinterpretation, misdiagnosis, and transportation and financial issues. Of these, misdiagnosis significantly influenced the delay rate, i.e., more than $50 \%$ of the misdiagnosed patients arrived hospital after six hours of symptom onset $(\mathrm{p}<0.05)$.

Review began 01/11/2021 Review ended 01/25/2021 Published 01/28/2021

\section{() Copyright 2021}

Mujtaba et al. This is an open access article distributed under the terms of the Creative Commons Attribution License CC-BY 4.0., which permits unrestricted use, distribution, and reproduction in any medium, provided the original author and source are credited.

\section{Conclusion}

The P-PCI rural satellite center had a positive impact as the observed pre-hospital delay rate was considerably less as compared to that reported in the existing literature. Moreover, the confounding factors were misdiagnosis and misinterpretations. We need to develop the concept of immediate appropriate helpseeking among patients.

Categories: Cardiology, Public Health

Keywords: st-elevation myocardial infarction, pre-hospital delay, primary percutaneous coronary intervention

\section{Introduction}

Acute Myocardial Infarction (AMI) remains a medical emergency and a common cause of mortality worldwide. Recommended treatment involves the restoration of blood flow as soon as possible. Reperfusion is achieved either with thrombolytic therapy or percutaneous coronary intervention (PCI) $[1,2]$.

As per the therapeutic guidelines, timely reperfusion is crucial. Therefore, thrombolysis should not be delayed for more than 30 minutes, and PCI to be performed within 90 minutes after arrival at the hospital (door-to-needle time and door-to-balloon time). Primary PCI (P-PCI) is considered superior to thrombolysis [3] as P-PCI has proven to be more efficacious for the cases with prolonged onsets to hospital arrival time. Total ischemia time (TIT), i.e., the time taken from the onset of pain till restoration of perfusion, plays an important role in overall prognosis [4]. Various measures and programs have been developed to cope with pre-hospital delays and enhance care quality [5]. Many developing countries now present the facility of PPCI capable hospitals with acceptable door-to-balloon time (DBT) [6,7]. Despite all these efforts, no significant reduction in the TIT has been observed until now as the pre-hospital delays, i.e., symptom-to- 
door time (STDT), remain the major barrier to reducing TIT [8].

For the first time in the province of Sindh (Pakistan), P-PCI-capable satellite centers have been established at strategic locations so that the majority of the patients can reach the facility within two hours by road. This study was aimed to determine the pre-hospital delay in patients with ST-Segment Elevation Myocardial Infarction (STEMI), its contributing factors, and its association with various baseline demographic characteristics. Results of the present study might help in reducing the overall disease burden by notifying the rate of pre-hospital delays and the associated factors. Very few studies on this subject have been conducted in developing countries [6-9].

\section{Materials And Methods}

This was a cross-sectional study that was conducted at a Rural Satellite Center (Larkana), Pakistan, from May to September 2020. The study conforms to the Declaration of Helsinki, and the protocol has been approved by the ethical review committee of the National Institute of Cardiovascular Diseases (Ref \#: ERC-16/2020). A total of 240 patients fulfilling the inclusion criteria were enrolled in this study after obtaining written informed consent. The inclusion criteria were patients of either gender between the ages of 20-60 years presenting with acute STEMI. In contrast, all patients with prior cardiac-related surgery, chronic kidney diseases (CKD), and congenital heart disease were excluded from the study. Patients who did not undergo PPCI were also excluded.

Data were collected using a structured questionnaire covering demographic characteristics, predisposing risk factors, care-seeking behaviour of the patients from symptom onset to hospital, reasons for delay presentation, and procedural.

STEMI is defined as chest pain along with ST-segment elevation in two contagious leads on an electrocardiogram (ECG). Patients with new-onset left bundle branch block (LBBB) and confirmed acute blockage of one of the major vessels on angiography were considered as confirmed STEMI cases. Coronary angiography was performed mostly through radial as the preferred route. The procedure was performed within 90 minutes of reaching the hospital, i.e., within 12 hours of the onset of chest pain. The aim was to open the culprit vessels and restore thrombolysis in myocardial infarction (TIMI) 3 flow. The decision regarding stenting and the type of stent was left on the treating consultant. In the case of hemodynamic instability, PCI of the non-culprit artery was undertaken at the consultant's discretion.

Collected data were entered and analyzed using SPSS version 21.0. (IBM Corp., Armonk, NY, USA). Patients were stratified based on symptom onset to hospital arrival time, and $\geqslant 6$ hours of symptom onset to hospital arrival time was considered late arrival. Descriptive statistics such as mean \pm standard deviation (SD) or median (interquartile range [IQR]) for continuous measures and frequency and percentages for categorical measures were calculated. Comparison between the two groups, late arrival and timely arrival groups, were made by applying independent sample t-test for continuous response and the Chi-Square test or Fisher's exact test for categorical response variable and significance criteria was $p \leqslant 0.05$.

\section{Results}

A total of 240 patients were included in this study, the majority (77.9\%) were males, and the overall mean age was $53.26 \pm 10.94$ years. The median [IQR] for symptom onset to hospital arrival was 120 [277.5 - 60] minutes. Among these, $20.4 \%$ of patients arrived late to the hospital ( $\geqslant 6$ hours) after symptoms onset. The distribution of patients according to symptom onset of hospital arrival time is presented in Figure 1. 


\section{Cureus}

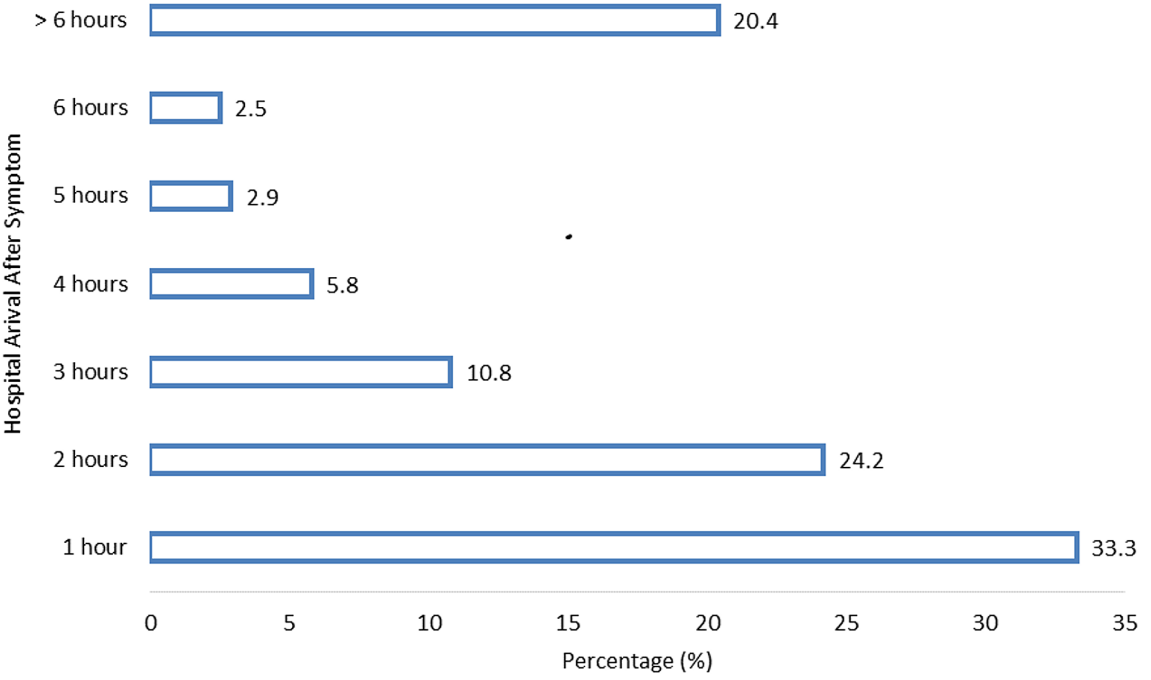

FIGURE 1: Distribution of patients according to symptom onset of hospital arrival time

Late arrival was associated with the female gender with a late arrival frequency of $35.8 \%$ (19/53) vs. 18.7\% (34/188), $p=0.008$, for female and male patients, respectively. The demographic characteristics of the patients stratified by hospital arrival status are presented in Table 1 . 


\section{Cureus}

\begin{tabular}{|c|c|c|c|c|c|}
\hline \multirow{2}{*}{ Variables } & & \multirow{2}{*}{ Total $\mathbf{N}=\mathbf{2 4 0}$} & \multicolumn{2}{|c|}{ Hospital arrival after symptoms } & \multirow{2}{*}{ p-value } \\
\hline & & & $\geq 6$ hours $(n=54)$ & $<6$ hours $(\mathrm{n}=186)$ & \\
\hline \multicolumn{2}{|l|}{ Age (years); mean \pm SD } & $53.26 \pm 10.94$ & $54.59 \pm 11.28$ & $52.87 \pm 10.84$ & 0.310 \\
\hline \multirow{3}{*}{ Age Groups } & $\leq 40$ years & $37(15.4)$ & $5(9.3)$ & $32(17.2)$ & \multirow{3}{*}{0.340} \\
\hline & 41 to 65 years & 177(73.8) & $42(77.8)$ & 135(72.6) & \\
\hline & $>65$ years & $26(10.8)$ & 7(13) & 19(10.2) & \\
\hline \multirow{2}{*}{ Gender } & Male & 187(77.9) & $35(64.8)$ & 152(81.7) & \multirow{2}{*}{$0.008^{*}$} \\
\hline & Female & $53(22.1)$ & 19(35.2) & $34(18.3)$ & \\
\hline \multirow{2}{*}{ Marital Status } & Married & $233(97.1)$ & $54(100)$ & 179(96.2) & \multirow{2}{*}{0.148} \\
\hline & Unmarried & $7(2.9)$ & - & $7(3.8)$ & \\
\hline \multirow{5}{*}{ Educational Status } & Illiterate & 20(8.3) & $5(9.3)$ & $15(8.06)$ & \multirow{5}{*}{0.894} \\
\hline & Primary & $52(21.6)$ & $11(20.3)$ & $41(22.04)$ & \\
\hline & Secondary & $34(14.1)$ & $8(14.8)$ & $26(13.9)$ & \\
\hline & Graduation & 40(16.6) & $7(2.91)$ & $33(17.7)$ & \\
\hline & Not Reported & 94(39.2) & - & - & \\
\hline \multirow{5}{*}{ Economic Condition } & Low Class & $65(27.0)$ & $15(27.7)$ & $50(26.8)$ & \multirow{5}{*}{0.646} \\
\hline & Lower Middle Class & 103(42.9) & 25(46.29) & $78(41.9)$ & \\
\hline & Middle Class & $51(21.25)$ & $8(14.8)$ & $43(23.1)$ & \\
\hline & Upper Middle Class & $16(6.6)$ & $4(7.4)$ & $12(6.45)$ & \\
\hline & Upper Class & $5(2.08)$ & 2(3.7) & $3(1.61)$ & \\
\hline \multirow{2}{*}{ Residence } & Urban & $56(23.3)$ & 12(22.2) & $44(23.7)$ & \multirow{2}{*}{0.826} \\
\hline & Rural & $184(76.7)$ & $42(77.8)$ & $142(76.3)$ & \\
\hline
\end{tabular}

\section{TABLE 1: Demographic characteristics}

${ }^{*} \mathrm{p}$-value $<0.05$ is considered significant.

SD: standard deviation.

A significantly higher proportion of late arrival patients had a first impression of non-cardiac chest pain with a frequency of $48.1 \%(26 / 54)$ vs. $32.8 \%$ (61/186); $p=0.039$. First medical contact to the cardiac care center was significantly lower among the late arrival patients than the patients who arrived within six hours of symptom, i.e., $16.7 \%(9 / 54)$ vs. $34.4 \%(64 / 186)$.

Moreover, contact with non-qualified local doctors had a significant role in delaying their presentation to the hospital $(\mathrm{p}=0.022)$. The majority of patients $(64.8 \%)$ who arrived at the hospital in $\geqslant 6$ hours were under the consultation of a local doctor, which significantly affected the hospital arrival rate. Furthermore, the mode of transfer had no significant effect on the pre-hospital delay ( $\mathrm{p}=0.163$ ). Symptom onset and careseeking behaviour of the patients are summarized in Table 2 . 


\section{Cureus}

\begin{tabular}{|c|c|c|c|c|}
\hline \multirow{2}{*}{ Variables } & \multirow{2}{*}{ Total $\mathbf{N}=\mathbf{2 4 0}$} & \multicolumn{2}{|c|}{ Hospital arrival after symptoms } & \multirow{2}{*}{ p-vlaue } \\
\hline & & $\geq 6$ hours $(n=54)$ & $<6$ hours $(\mathrm{n}=186)$ & \\
\hline \multicolumn{5}{|c|}{ First impression of symptoms } \\
\hline Cardiac Pain & 153(63.8) & $28(51.9)$ & 125(67.2) & \multirow{2}{*}{$0.039^{*}$} \\
\hline Non Cardiac pain & $87(36.3)$ & $26(48.1)$ & $61(32.8)$ & \\
\hline \multicolumn{5}{|c|}{ Non-cardiac impression of symptoms ${ }^{\star \star}$} \\
\hline Gastric & $50(57.5)$ & 14(53.8) & $36(59)$ & \multirow{4}{*}{0.450} \\
\hline Muscular & 13(14.9) & $3(11.5)$ & 10(16.4) & \\
\hline Tension & $9(10.3)$ & $2(7.7)$ & $7(11.5)$ & \\
\hline Others & 15(17.2) & $7(26.9)$ & $8(13.1)$ & \\
\hline \multicolumn{5}{|c|}{ Preferred treatment options } \\
\hline Home based treatment & $83(34.5)$ & $15(27.7)$ & 68(26.5) & \multirow{2}{*}{0.232} \\
\hline Contacted local doctor & 157(65.4) & $39(72.2)$ & 118(63.4) & \\
\hline \multicolumn{5}{|c|}{ First medical contact (FMC) } \\
\hline Local Doctor & $113(47.1)$ & $35(64.8)$ & 78(41.9) & \multirow{4}{*}{$0.022^{*}$} \\
\hline Local Hospital & 29(12.1) & $6(11.1)$ & 23(12.4) & \\
\hline Tertiary Care Hospital & 25(10.4) & $4(7.4)$ & $21(11.3)$ & \\
\hline Cardiac Care Center & $73(30.4)$ & $9(16.7)$ & $64(34.4)$ & \\
\hline \multicolumn{5}{|l|}{ Mode of transfer } \\
\hline Personal Vehicle & $74(30.8)$ & $12(22.2)$ & 62(33.3) & \multirow{4}{*}{0.163} \\
\hline Taxi & 124(51.7) & $33(61.1)$ & 91(48.9) & \\
\hline Ambulance & $7(2.9)$ & - & $7(3.8)$ & \\
\hline Other & $35(14.6)$ & $9(16.7)$ & $26(14)$ & \\
\hline
\end{tabular}

\section{TABLE 2: Symptom onset and care-seeking}

**Based on patients with the first impression of non-cardiac pain.

${ }^{*} \mathrm{p}<0.05$ is considered significant.

Among the major reasons for the pre-hospital delay, misdiagnosis and transportation were significant predictors $(\mathrm{p}<0.05)$. No significant effects of misinterpretations and financial issues were observed on the late hospital arrival. Most patients managed to arrive at the hospital in $<6$ hours, even with existing misinterpretations and financial issues $(\mathrm{p}=0.90)$ (Table 3). 


\begin{tabular}{|c|c|c|c|c|}
\hline \multirow{2}{*}{ Reasons for delay } & \multirow{2}{*}{ Total $\mathbf{N}=\mathbf{2 4 0}$} & \multicolumn{2}{|c|}{ Hospital arrival after symptoms } & \multirow{2}{*}{ p-value } \\
\hline & & $\geq 6$ hours $(n=54)$ & $<6$ hours $(\mathrm{n}=186)$ & \\
\hline Misinterpretation & $65(33)$ & $19(29.2)$ & $46(70.7)$ & 0.090 \\
\hline Misdiagnosis & 29(21.4) & $16(55.1)$ & $13(44.8)$ & $0.000^{*}$ \\
\hline Transportation & $99(31.1)$ & $13(13.1)$ & $86(86.8)$ & $0.002^{\star}$ \\
\hline Financial & 10(3.9) & 1(10) & $9(90)$ & 0.299 \\
\hline Others & $38(10.7)$ & $5(13.1)$ & $33(86.8)$ & 0.094 \\
\hline
\end{tabular}

TABLE 3: Reasons for pre-hospital delay in patients with acute ST-segment myocardial infarction undergoing PPCI

${ }^{*} \mathrm{p}$-value $<0.05$ is considered significant.

PPCI: Primary Percutaneous Coronary Intervention.

\section{Discussion}

The importance of time in the management of myocardial infarction cannot be underestimated. Both mortality and morbidity are directly proportional to the time taken from the onset of symptoms to the start of reperfusion therapy. There are two main treatment modalities of reperfusion therapy: either thrombolysis with pharmacologic drugs or physical removal of clot by the coronary intervention. Thrombolysis is most commonly employed in developing countries. One study from India showed that almost $90 \%$ of patients receive thrombolysis than $10 \%$ receiving P-PCI [10]. Time is a crucial prognostic marker, whatever treatment option is employed. However, successful reperfusion with thrombolysis is more time-dependent than PCI.

Studies have shown that a major benefit is when patients are perfused within one hour of symptom onset $[11,12]$. While patients presenting later than 12 hours of symptom onset have no benefit or, in some cases, it exposes them to harm, especially in old-age patients $[13,14]$.

In our study, the observed pre-hospital time (PHT) was 120 minutes (median); 229 (IQR). The data from the CREATE registry of acute coronary syndrome patients involving 89 large hospitals in 10 different regions and cities across India presented a PHT of 300 minutes (137-985) [10]. A more recent study from Bangladesh reported the median pre-hospital delay of nine (IQR 13) hours [15]. Though symptom onset to reperfusion therapy time less than two hours is considered ideal, other studies have shown only $22-44 \%$ of patients present to the hospital within two hours of chest pain onset [16-18].

In our study, almost $33.3 \%$ of AMI patients arrived hospital during the first hour after the symptom onset, $46.25 \%$ arrived during two to six hours, and $20.4 \%$ presented late, i.e., after six hours of symptom onset. We deliberately selected a cut-off of six hours to label as late, which was used in most studies conducted in developing countries [6]. Our study showed that almost $10 \%$ of patients presented even after 12 hours. Other studies showed that almost 10-25\% of patients arrived after 12 hours [19-21].

Pre-hospital delay is comparatively more as compared to Western countries [22,23]. Short pre-hospital delays in Western countries can be attributed to their well-organized health care system. Early recognition, easy accessibly to hospitals, and early detection are all factors related to a well-organized health care system. One of the major reasons for the pre-hospital delay was the patient's decision time. Almost one-third of the patients misperceived the symptoms. Among them, 50\% linked the symptoms to the gastric problem. Similarly, an Indian study also displayed misperception as one of the prominent reasons for the pre-hospital delay, i.e., $24 \%$ of their patients considered chest pain of myocardial infarction as gastritis, and $6 \%$ perceived it to be a muscular pain [24]. Other studies have also shown that PHT is much reduced when the initial perception of pain is related to a cardiac source rather than a non-cardiac source of pain [7,9].

Ischemic heart disease is commonly considered a disease of urban society. As most of our study population was from rural areas, the cardiac origin of pain might have been neglected due to lack of knowledge as misperceived as gastric pain, which is commonly treated with home remedies. Almost $30 \%$ of the enrolled patients initially took some home-based remedy for symptomatic relief, resulting in delayed PHT.

The current study showed that approximately $79 \%$ of the total pre-hospital delays were due to patientrelated factors, and only $21 \%$ of the delays were due to transportation. They also showed that a good number of hours are wasted prior to physician consultation [25]. One solution is large scale programs of awareness of 
heart attack symptoms and signs. The population should be made aware to immediately contact the doctor with an ECG facility to diagnose AMI to initiate prompt management. But previously, large scale education programs for awareness about myocardial infarction symptoms have not proved to be significantly decreasing the PHT.

A recent systematic review of 10 studies aiming to reduce pre-hospital delay times concluded that there was little evidence that public education interventions reduced pre-hospital delay [26]. Similarly, the REACT study carried out from 1995 to 1997 in 20 American cities concluded that although persons living in the target areas of the public information campaigns were demonstrably better informed about the subject afterwards; however, the PHTs in the target areas were not shortened significantly in comparison to control areas [27].

One justification can be that these studies were conducted in developed nations where education and awareness level was already optimum, and similar programs would likely bear fruitful results in our population with low literacy. Transportation was also a major reason for late arrival. Our study population mostly consisted of rural areas. This area has not a well-established system of roads. Transport means are mostly private owned or taxis. Finding a taxi is sometimes difficult in rural areas. The widespread use of mobile phones has made somewhat things better. A reason for delays due to transportation is the lack of an organized ambulance service. Practically no organized ambulance service is available at the government level. Therefore the patient has to be carried to the hospital via self-transportation.

The third reason was misdiagnosis at the primary consultation point. Due to the lack of a well-functioning primary health care system, only $10 \%$ went to a local hospital in our study. Almost $50 \%$ of the patients went to a local doctor. These local doctors are mostly medical graduates. They work as family physicians. Most of the time, they are not well trained in cardiology or lack basic equipment like ECG. Therefore the misdiagnosis rate is high. Thus, there is a strong need for these primary health care providers to identify signs and symptoms of myocardial infarction and be equipped with an ECG facility.

\section{Conclusions}

In conclusion, the enrolled STEMI patients presented to the Rural Satellite Center in Larkana, Pakistan, displayed relatively short pre-hospital delay time as compared to other reports from developing countries. Symptom impressions, contact with non-qualified practitioners and misdiagnosis had a significant role in delaying the hospital arrival. It is crucial to develop an adequate health care delivery system to relay effective and timely diagnosis and treatment. Moreover, public awareness is also very important to reduce pre-hospital delay.

\section{Additional Information \\ Disclosures}

Human subjects: Consent was obtained or waived by all participants in this study. National Institute of Cardiovascular Diseases issued approval ERC-16/2020. The study conforms to the Declaration of Helsinki and the protocol has been approved by the ethical review committee of the National Institute of Cardiovascular Diseases (Ref \#: ERC-16/2020). . Animal subjects: All authors have confirmed that this study did not involve animal subjects or tissue. Conflicts of interest: In compliance with the ICMJE uniform disclosure form, all authors declare the following: Payment/services info: All authors have declared that no financial support was received from any organization for the submitted work. Financial relationships: All authors have declared that they have no financial relationships at present or within the previous three years with any organizations that might have an interest in the submitted work. Other relationships: All authors have declared that there are no other relationships or activities that could appear to have influenced the submitted work.

\section{Acknowledgements}

The authors are thankful to Ms. Mahwish Raza for her support throughout the study duration.

\section{References}

1. Eagle KA, Goodman SG, Avezum A, et al.: Practice variation and missed opportunities for reperfusion in STsegment-elevation myocardial infarction: findings from the Global Registry of Acute Coronary Events (GRACE). Lancet Lond Engl. 2002, 359:373-377. 10.1016/S0140-6736(02)07595-5

2. Arif M, Saleem Y, Riaz S, et al.: Young adults undergoing coronary artery bypass grafting (CABG). Int J Endorsing Health Sci Res. 2020, 8:41-46. 10.29052/IJEHSR.v8.i1.2020.41-46

3. Janda SP, Tan N: Thrombolysis versus primary percutaneous coronary intervention for ST elevation myocardial infarctions at Chilliwack General Hospital. Can J Cardiol. 2009, 25:382-384. 10.1016/s0828 $282 x(09) 70165-5$

4. De Luca G, Suryapranata H, Ottervanger JP, Antman EM: Time delay to treatment and mortality in primary angioplasty for acute myocardial infarction: every minute of delay counts. Circulation. 2004, 109:12231225. 10.1161/01.CIR.0000121424.76486.20

5. Mohanan PP, Mathew R, Harikrishnan S, et al.: Presentation, management, and outcomes of 25748 acute 
coronary syndrome admissions in Kerala, India: results from the Kerala ACS Registry. Eur Heart J. 2013, 34:121-129. 10.1093/eurheartj/ehs219

6. Rajagopalan RE, Chandrasekaran S, Pai M, Rajaram R, Mahendran S: Pre-hospital delay in acute myocardial infarction in an urban Indian hospital: a prospective study. Natl Med J India. 2001, 14:8-12.

7. Khan A, Phadke M, Lokhandwala YY, Nathani PJ: A study of prehospital delay patterns in acute myocardial infarction in an urban tertiary care institute in Mumbai. J Assoc Physicians India. 2017, 65:24-27.

8. Beig JR, Tramboo NA, Kumar K, et al.: Components and determinants of therapeutic delay in patients with acute ST-elevation myocardial infarction: a tertiary care hospital-based study. J Saudi Heart Assoc. 2017, 29:7-14. 10.1016/j.jsha.2016.06.001

9. Gao Y, Zhang H: The effect of symptoms on pre-hospital delay time in patients with acute myocardial infarction. J Int Med Res. 2013, 41:1724-1731. 10.1177/0300060513488511

10. Xavier D, Pais P, Devereaux PI, et al.: Treatment and outcomes of acute coronary syndromes in India (CREATE): a prospective analysis of registry data. Lancet Lond Engl. 2008, 371:1435-1442. 10.1016/S01406736(08)60623-6

11. Boersma E, Maas AC, Deckers JW, Simoons ML: Early thrombolytic treatment in acute myocardial infarction: reappraisal of the golden hour. Lancet Lond Engl. 1996, 348:771-775. 10.1016/S0140-6736(96)02514-7

12. Taher T, Fu Y, Wagner GS, et al.: Aborted myocardial infarction in patients with ST-segment elevation: insights from the assessment of the safety and efficacy of a new thrombolytic regimen-3 trial electrocardiographic substudy. J Am Coll Cardiol. 2004, 44:38-43. 10.1016/j.jacc.2004.03.041

13. LATE Study Group: Late Assessment of Thrombolytic Efficacy (LATE) study with alteplase 6-24 hours after onset of acute myocardial infarction. Lancet. 1993, 342:759-766. 10.1016/0140-6736(93)91538-W

14. Randomized trial of late thrombolysis in patients with suspected acute myocardial infarction. EMERAS (Estudio Multicéntrico Estreptoquinasa Repúblicas de América del Sur) Collaborative Group. Lancet. 1993, 342:767-772.

15. Rafi A, Sayeed Z, Sultana P, Aik S, Hossain G: Pre-hospital delay in patients with myocardial infarction: an observational study in a tertiary care hospital of northern Bangladesh. BMC Health Serv Res. 2020, 20:633. 10.1186/s12913-020-05505-X

16. Goldberg RJ, Steg PG, Sadiq I, et al.: Extent of, and factors associated with, delay to hospital presentation in patients with acute coronary disease (the GRACE registry). Am J Cardiol. 2002, 89:791-796. 10.1016/s00029149(02)02186-0

17. Goldberg RJ, Yarzebski J, Lessard D, Gore JM: Decade-long trends and factors associated with time to hospital presentation in patients with acute myocardial infarction: the Worcester Heart Attack study. Arch Intern Med. 2000, 160:3217-3123. 10.1001/archinte.160.21.3217

18. Pitsavos C, Kourlaba G, Panagiotakos DB, Stefanadis C: Factors associated with delay in seeking health care for hospitalized patients with acute coronary syndromes: the GREECS study. Hell J Cardiol. 2006, 47:329336.

19. Ottesen MM, Dixen U, Torp-Pedersen C, Køber L: Prehospital delay in acute coronary syndrome--an analysis of the components of delay. Int J Cardiol. 2004, 96:97-103. 10.1016/j.ijcard.2003.04.059

20. Gurwitz JH, McLaughlin TJ, Willison DJ, et al.: Delayed hospital presentation in patients who have had acute myocardial infarction. Ann Intern Med. 1997, 126:593-599. 10.7326/0003-4819-126-8-199704150-00001

21. Sheifer SE, Rathore SS, Gersh BJ, Weinfurt KP, Oetgen WJ, Breall JA, Schulman KA: Time to presentation with acute myocardial infarction in the elderly: associations with race, sex, and socioeconomic characteristics. Circulation. 2000, 102:1651-1656. 10.1161/01.cir.102.14.1651

22. Gärtner C, Walz L, Bauernschmitt E, Ladwig K: The causes of prehospital delay in myocardial infarction . Dtsch Arzteblatt Int. 2008, 105:286-291. 10.3238/arztebl.2008.0286

23. McKinley S, Dracup K, Moser DK, Ball C, Yamasaki K, Kim CJ, Barnett M: International comparison of factors associated with delay in presentation for AMI treatment. Eur J Cardiovasc Nurs. 2004, 3:225-230. 10.1016/j.ejcnurse.2004.06.004

24. Mohan B, Bansal R, Dogra N, et al.: Factors influencing pre-hospital delay in patients presenting with STelevation myocardial infarction and the impact of pre-hospital electrocardiogram. Indian Heart J. 2018, 70:194-198. 10.1016/j.ihj.2018.10.395

25. Choudhary R, Sharma S, Kumar V, Gautam DK: An observational study of pre-hospital and hospital delay in reperfusion for acute myocardial infarction at a university hospital in India. J Pract Cardiovasc Sci. 2016, 2:163-168. 10.4103/2395-5414.201378

26. Kainth A, Hewitt A, Sowden A, et al.: Systematic review of interventions to reduce delay in patients with suspected heart attack. Emerg Med J. 2004, 21:506-508. 10.1136/emj.2003.013276

27. Luepker RV, Raczynski JM, Osganian S, et al.: Effect of a community intervention on patient delay and emergency medical service use in acute coronary heart disease: the Rapid Early Action for Coronary Treatment (REACT) trial. JAMA. 2000, 284:60-67. 10.1001/jama.284.1.60 